\title{
Penile Epidermoid Cyst Consisted of Multiple Foci: A Case Report
}

\author{
Akiou Okumura $^{1}$, Kiyoshi Takagawa ${ }^{2}$, Hideki Fuse ${ }^{3}$ \\ ${ }^{1}$ Department of Urology, Kurobe City Hospital, Toyama, Japan; ${ }^{2}$ Department of Clinical Laboratory, Kurobe City Hospital, Toyama, \\ Japan; ${ }^{3}$ Department of Urology, Graduate School of Medicine and Pharmaceutical Sciences for Research, University of Toyama, \\ Toyama, Japan. \\ Email: okumura@med.kurobe.toyama.jp
}

Received May $15^{\text {th }}, 2012$; revised June $21^{\text {st }}, 2012$; accepted July $6^{\text {th }}, 2012$

\begin{abstract}
Penile epidermoid cysts are uncommon, and a small number of cases have been reported worldwide. We present the first documented patient with a penile epidermoid cyst which consisted of multiple foci. A 37-year-old man presented to our department with a chief complaint of an asymptomatic, soft mass in the ventral part of the penis. The mass was not tender, freely movable and measuring $3 \mathrm{~cm}$ within the dermis. MRI (magnetic resonance imaging) revealed a high signal intensity on both T1- and T2-weighted images. Excision of the cyst was performed under local anesthesia. Macroscopically, the cut surface of the mass appeared to be full of a cheese-like material and the cyst consisted of multiple foci. The cyst did not contain skin appendages. The pathological diagnosis was an epidermoid cyst of the penis. No recurrence has been noted in the year since the operation.
\end{abstract}

Keywords: Penis; Epidermoid Cyst; Multiple Foci

\section{Introduction}

Epidermoid cysts are the most common cutaneous cysts, and these lesions can be found anywhere on the body, including the genitalia [1]. They are particularly common on the scrotum. On the other hand, penile epidermoid cysts are uncommon and usually congenital. The etiology is unknown, but it may represent a monolayer teratoma of germ cell origin or an abnormal embryogenic closure of the median raphe [2-4]. We report the first documented case of a penile epidermoid cyst which consisted of multiple foci.

\section{Case Report}

A 37-year-old man presented to our department with a chief complaint of an asymptomatic, soft mass in the ventral part of the penis (Figure 1). He had no history of penile trauma, inflammation, urinary tract infection, hematuria or dysuria. The mass was not tender, freely movable, and measuring $3 \mathrm{~cm}$ within the dermis. MRI revealed a high signal intensity on both T1- and T2-weighted images within the ventral part of the penis, indicating concentrated proteinic fluid within the cyst (Figure 2). MRI highly suggested an epidermoid cyst of the penis.

Excision of the cyst was performed under local anesthesia. Macroscopically, the cut surface of the mass ap-

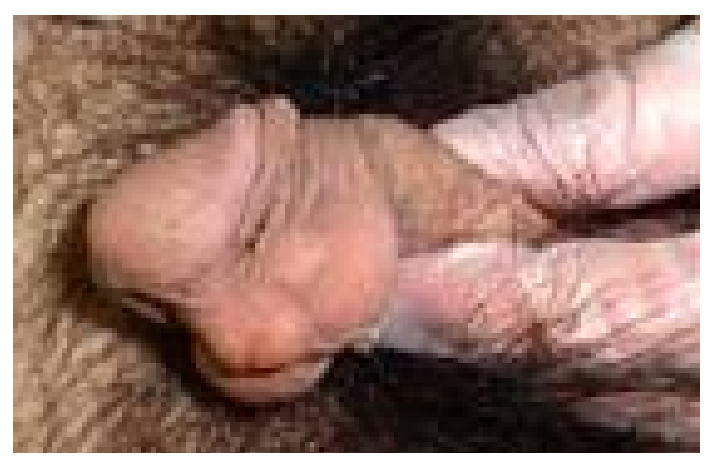

Figure 1. Soft mass in the ventral part of the penis.

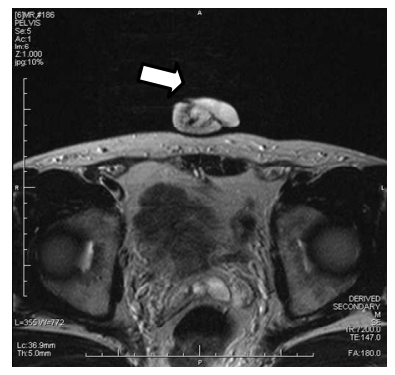

(a)

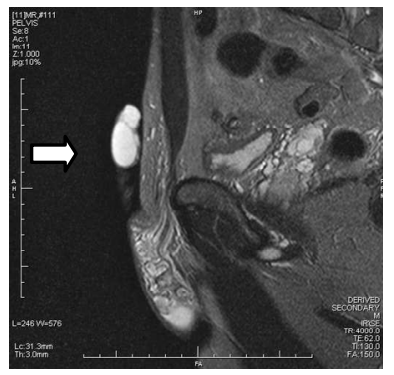

(b)
Figure 2. MRI revealed high signal by T1 emphatic intensity image within the ventral part of the penis. Arrows indicate the cyst of the penis. (a) Transverse section; (b) Sagital section. 
peared to be full of a cheese-like material and the cyst consisted of multiple foci. Histological examination revealed that the wall was lined with squamous epithetlium and laminated keratin (Figure 3). The cyst did not contain skin appendages. The pathological diagnosis was an epidermoid cyst of the penis. No recurrence has been noted in the year since the operation.

\section{Discussion}

Penile epidermoid cysts are uncommon, and a small number of cases have been reported worldwide. Histologically, they are lined by well-developed stratified epithelium without a skin appendage, and are composed of keratin-producing epithelium [4,5]. Although the etiology is unknown, some reports have suggested that the cyst may originate from a median raphe cyst, possibly arising from abnormal embryological closure of the median raphe or, rarely, may be acquired after mechanical implantation such as that involving the injection of an epidermal fragment [4,6]. Khanna [7] proposed the criteria for a penile epidermoid cyst, whereby the cyst should be: 1) surrounded by penile tissue; 2) filled with keratin only; 3) lined with surrounding fibrous connective tissue; 4) and with an inner lining of stratified squamous epithelium and without dermal appendages. This case fulfilled all these criteria.

Penile cysts or male genital cystic diseases occur in the various sizes, but they are usually solitary. Among the diseases, urethral diverticula and urethrocutaneous fistula are important, but can usually be ruled out by both physical examination and the conditions evident upon voiding [4]. Unlike urethal diverticula, epidermoid cysts do not

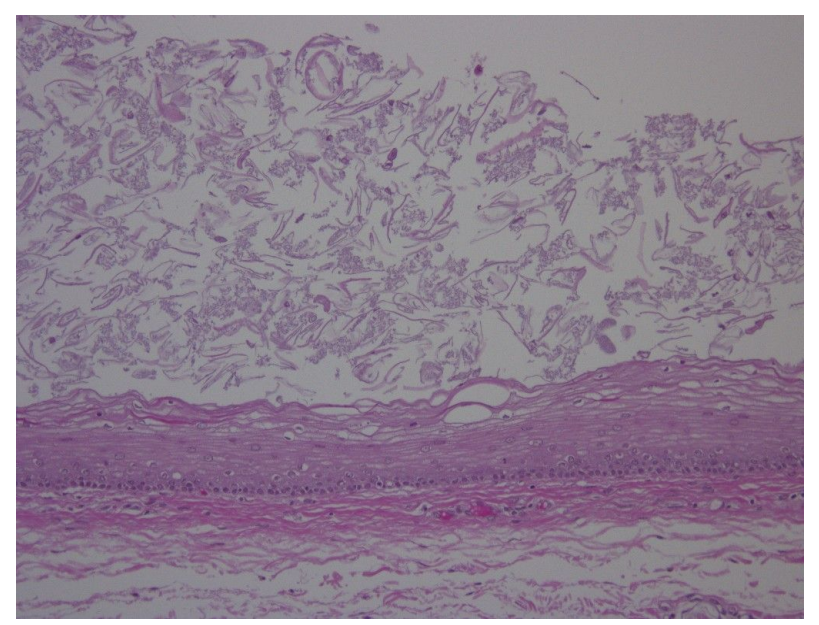

Figure 3. Histological aspect of the wall. The wall was lined with squamous epithelium and laminated keratin (H-E). communicate with the urethra. In our case, the cyst did not communicate with the urethra and did not affect urination. Although rare, the extension of a cyst into the pelvis has been reported [8]. In such cases, MRI is the most useful modality for depicting the boundaries of the lesion [8]. In this case, MRI was useful to clarify the margin of the disease and investigate the characteristics of the cyst.

In treatement for an epidermoid cyst, simple complete excision has been regarded as the best treatment procedure [4]. Although they are usually not painful, rupture of the cyst wall can lead to a severe inflammatory reaction that is extremely painful, and definitive treatment requires surgical excision of the entire cyst wall to prevent cyst recurrence [1]. Aspiration or simple drainage may carry a risk of recurrence. There have been no reported cases of malignancy involving a penile epidermoid cyst. This case is the first penile epidermoid cyst to be reported which consisted of multiple foci.

\section{REFERENCES}

[1] R. E. Link, "Cutaneous Diseases of the External Genitalia,” In: A. J. Wein, L. R. Kavoussi, A. C. Novick, A. W. Partin and C. A. Peters, Eds., Campbell's Urology, 10th Edition, W. B. Saunders Co., Philadelphia, 2012, pp. 436467.

[2] J. H. Ross, R. Kay and J. Elder, "Testis Sparing Surgery for Pediatric Epidermoid Cysts of the Testis," The Journal of Urology, Vol. 149, No. 2, 1993, pp. 353-356.

[3] S. S. Shah, E. G. Varea, A. Farsaii, R. Femandez, C. Richardson and H. Shutte, "Giant Epidermoid Cyst of Penis," Urology, Vol. 14, No. 4, 1979, pp. 389-391. doi:10.1016/0090-4295(79)90089-X

[4] M. Suwa, M. Takeda, V. Bilim and K. Takahashi, "Epidermoid Cyst of the Penis: A Case Report and Review of the Literature," International Journal of Urology, Vol. 7, No. 11, 2000, pp. 431-433. doi:10.1046/j.1442-2042.2000.00219.x

[5] J. Rattan, S. Rattan and D. K. Gupta, "Epidermoid Cyst of the Penis with Extention into the Pelvis," The Journal of Urology, Vol. 158, No. 2, 1997, p. 593. doi:10.1016/S0022-5347(01)64562-2

[6] C. Laurenti and C. De Dominicis, "A Cyst in the Penis of a Child," British Journal of Urology, Vol. 50, No. 3, 1978, p. 213.doi:10.1111/j.1464-410X.1978.tb02808.x

[7] S. Khanna, "Epidermoid Cyst of the Glans Penis," European Urology, Vol. 19, No. 2, 1991, pp. 176-177.

[8] B. Salder, S. P. Greenfield, J. Wan and P. L. Glick, "Intrascrotal Epidermoid Cyst of with Extention into the Pelvis," The Journal of Urology, Vol. 153, No. 4, 1995, pp. 1265-1266. doi:10.1016/S0022-5347(01)67583-9 